Review - Pregledni rad

UDK: 637.073

\title{
Application of electronic nose and electronic tongue in the dairy industry
}

\author{
doi: $10.15567 /$ mljekarstvo.2014.0402 \\ Milna Tudor Kalit ${ }^{1}$, Ksenija Markovićㄹ, Samir Kalit ${ }^{*}$, \\ Nada Vahčić ${ }^{2}$ Jasmina Havranek ${ }^{1}$ \\ ${ }^{1}$ University of Zagreb, Faculty of Agriculture, Department of Dairy Science, \\ Svetošimunska 25, 10000 Zagreb, Croatia \\ ${ }^{2}$ University of Zagreb, Faculty of Food Technology and Biotechnology, Department of Food Quality \\ Control, Pierottijeva 6, 10000 Zagreb, Croatia \\ Received - Prispjelo: 23.04.2014. \\ Accepted - Prihvaćeno: 12.09.2014.
}

\begin{abstract}
Electronic nose (e-nose) and electronic tongue (e-tongue) instrumental systems were designed to crudely mimic human olfactory and taste sensory organs and are composed of an array of sensors. Complex data sets from electronic nose and electronic tongue signals combined with multivariate statistics represent rapid and efficient tools for classification, discrimination, recognition and identification of samples, as well as for the prediction of concentrations of different compounds. A wide variety of sensors can be employed into the design of these instrumental systems, especially that of electronic tongues, offering numerous practical applications. In this study, characteristics of sensors and possibilities of electronic nose and electronic tongue applications in the dairy industry were reviewed.
\end{abstract}

Key words: electronic nose, electronic tongue, dairy industry, classification, discrimination

\section{Introduction}

Sensory quality of food refers to a set of characteristics such as appearance, colour, taste, smell, aroma, texture and auditory properties. Each of the above characteristics can be viewed separately, but together they represent an important food quality determinant (Piggott, 1994; O'Riordan and Delahunty, 2003; Biolatto et al., 2007). Aroma is the most important factor influencing consumers' purchase intent, estimation of food quality and food acceptance (Bakker, 1997; Santonico et al., 2008). It is a specific sensory characteristic detected when volatile compounds enter the nasal portion of the olfactory system down through the back of the throat and get to be detected by olfactory receptors (Gomez et al., 2006). Despite the importance of aroma as a food quality indicator, quality and acceptability of a product are traditionally monitored in food industry settings by virtue of production processes' control via physicochemical measurements such as $\mathrm{pH}$-value and colour, as well as by virtue of spectroscopic determination of concentrations of particular molecules. This is mainly due to the practical inability of continuous instrumental aroma assessment during the entire production process (i.e. using chromatography), as well as due to the need for employment of sensory panels. All of these practical problems were overcome by the invention of Persaud and Dodd. In the year 1982 they constructed a device that imitates the mammalian nose, called "the electronic nose" ("e-nose"). A similar system, but mimicking the sense of taste, was presented by Toko and co-workers (Hayashi et al., 1990). For this concept of transformation 
of taste quality information (sweetness, bitterness, sourness, saltiness or umami) into an electric signal, the terms "electronic tongue" ("e-tongue") or "taste sensor" have been coined (Hayashi et al., 1990; Toko, 1998; Tian et al., 2007).

The main advantage of an electronic nose is that, once calibrated, it can continuously assess aroma throughout the whole production process at minimal costs (Ampuero and Bosset, 2003). Besides that, instrumental techniques can be time-consuming and expensive, and require skilled personnel. Therefore, the usage of an electronic nose and electronic tongue can represent a good indirect food quality measurement option (Trihaas et al., 2005). However, an electronic nose, as well as an electronic tongue, does not provide information on the nature of constituting compounds, but only give a digital fingerprint of the food that can be investigated by means of multivariate statistical analysis (Cosio et al., 2006). This is why the use of electronic nose and electronic tongue cannot become more than just a method complementary to sensory analysis (Hodgins, 1997; Gutiérrez-Méndez et al., 2008). Combined with pattern recognition techniques, an electronic nose represents a rapid and efficient tool for the classification of volatile compounds with no need for previous separation procedures (Cerrato Oliveros et al., 2002); unlike traditional analytical methods, this technique is comparison- rather than separationbased (O'Riordan and Delahunty, 2003). Except in food industry, electronic nose and electronic tongue found their application in car industry, medicine, military industry, space technology, wastewater treatment, pharmacy, agriculture and chemistry.

Milk and dairy products' aroma profiles are defined by a complex mixture of volatiles at different levels that can be affected by milk composition that depends, among other, on dairy cattle management (genetics, herd health and feeding regimens) and milk manufacturing process (Biolatto et al., 2007). The type of milk used for its production and the ripening process are the main factors that determine the characteristic cheese aroma (Cabezas et al., 2007). Industrial quality and commercial success of dairy products can be severely affected by microbial milk spoilage, which can lead to the production of undesirable off-flavours, physical defects and secondary metabolite toxicity (Magan et al., 2001). Given the above reasons, electronic nose and electronic tongue can be very helpful in the analysis of volatile and non-volatile compounds of dairy products, in order to monitor their quality. Therefore, the aim of the present paper is to review possible electronic nose and electronic tongue applications in dairy industry.

\section{The electronic nose concept}

The term "electronic nose" comes from the similarities with the mammalian olfactory system. This instrument imitates the performance of the mammalian olfactory system and determines the aroma profile through the determination of the total profile of food volatile components. It is composed of an array of non-selective sensors which transform chemical information into an electrical (resistance, voltage, frequency) or optical one (colour); such an information then gets to be transformed into a digital form suitable for computer processing (Figure 1). Upon being sniffed or entered via the retro-nasal pathway if a product is tasted, volatile compounds reach the olfactory epithelium where, as a result of the interaction between volatile compounds and chemosensory receptors (olfactory neurons), electrical stimuli arise and are transmitted into the brain (Gostelow et al., 2001; Ampuero and Bosset, 2003).

Each olfactory neuron has the ability to respond to several odorants; on the other hand, each odorant can be detected by multiple olfactory neurons (A1bert et al., 2000; Ampuero and Bosset, 2003). Electronic noses operate under the same principle. Products of similar aroma evoke similar sensory responses, meaning that their "fingerprints" are similar, while those of different aroma have mutually different "fingerprints".

In general, the analysis in the electronic nose is conducted by placing the product into an airtight glass jar (concentration chamber), where the product should be kept for approximately one hour to release volatile components. By a syringe through the jar cover, an aliquot of the sample headspace is pumped over the electronic nose sensors. The measurement phase lasts for 60 seconds; after that, a stand-by phase is activated so as to clean the system and reset the sensors back to their baseline level. This is accomplished by virtue of pumping fresh air into the system; the air first crosses the sensors and then reaches the empty concentration chamber (Gomez et al., 2007). The scheme of an electronic nose is 


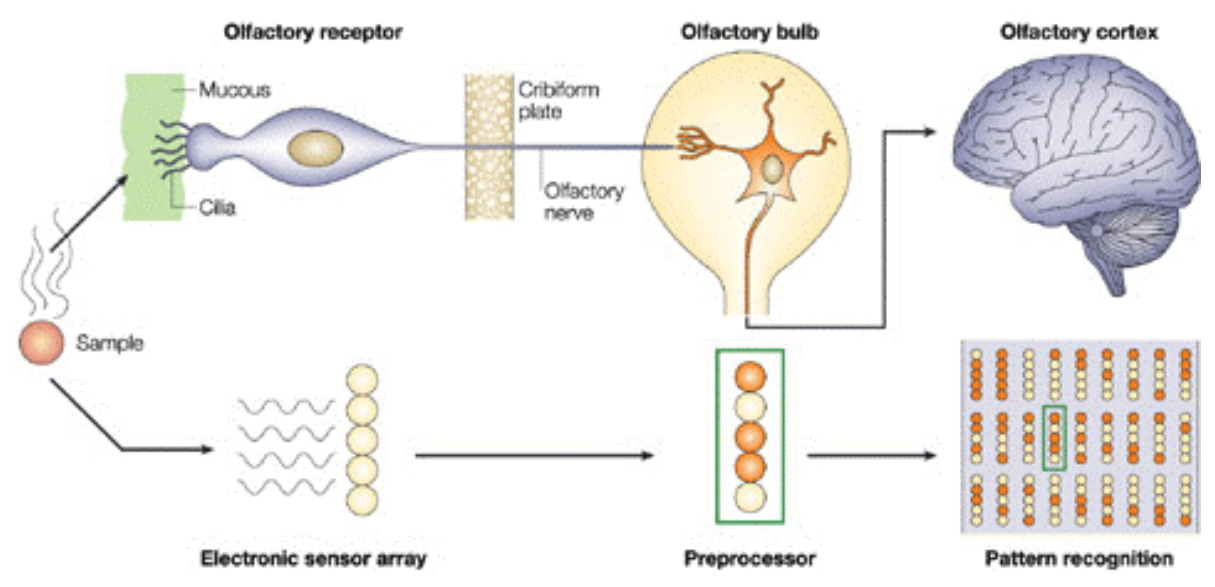

Figure 1. Comparison of an electronic nose and human brain performance (Turner and Magan, 2004)

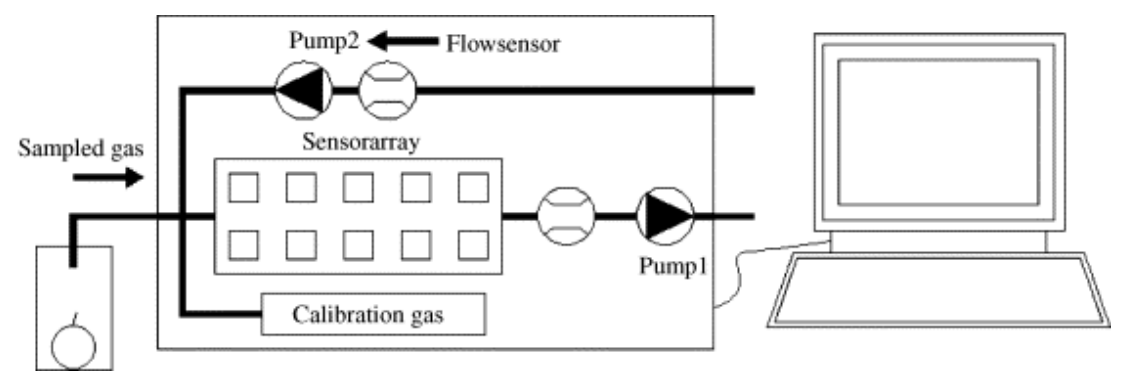

Figure 2. Electronic nose scheme (Gomez et al., 2008)

shown in Figure 2. The interaction between volatiles and sensors triggers a series of signals which are processed by the computer via an algorithm pattern recognition program. The most widely used pattern recognition models are Principal Component Analysis (PCA), Linear Discriminant Analysis (LDA) and Artificial Neural Network (ANN) (Giese, 2000; Ampuero and Bosset, 2003; Deisingh et al., 2004).

\section{The electronic tongue concept}

Recently, similar concepts, but used for liquid analysis, have been described. These systems mimic the sense of taste; thus, the terms "electronic tongue" (e-tongue) or "taste sensor" have been coined. Generally speaking, an electronic tongue or a taste sensor functions in a manner similar to that of an electronic nose, that is to say, the sensor array produces signals which are not necessarily specific to a particular species, but do form a pattern that can be correlated to certain features or qualities of the sample (Winquist et al., 1997; Winquist et al., 2002).
Electronic tongues crudely mimic human taste receptors and their communication with the human brain. Human taste sensation comes as a result of physico-chemical interactions between food molecules and a complex system of hundreds of taste buds spread over the tongue and constituted of taste cells capable of recognising sweet, acid, bitter, salty, and umami taste. An electronic tongue is generally tested for its capability of recognising the following standard tastes: sweet, acid, bitter, salty, and umami. An electronic tongue uses a range of sensors that respond to salts, acids, sugars, bitter compounds, etc. Interpretation of complex data sets generated by electronic tongue signals is accomplished by use of multivariate statistics including PCA, LDA, discriminant function analysis (DFA), hierarchical cluster analysis (HCA), soft independent modelling of class analogy (SIMCA) and partial least squares (PLS). For non-linear responses, ANN can be used for data modelling (Baldwin et al., 2011). The main purpose of electronic tongues is qualitative analysis, such as recognition, classification or identification of 
samples, which depends on the composition of the sensor array and the mathematical procedure chosen for data processing (Dias et al., 2009).

\section{Type and characteristics of electronic nose sensors}

Metal oxide sensors (MOS)

Metal oxide sensors consist of a ceramic substrate coated with metal-oxide semiconducting film (e.g. $\mathrm{SnO}_{2}, \mathrm{TiO}_{2}, \mathrm{ZnO}, \mathrm{ZrO}_{2}$ ) which reacts with oxygen from the air. During this reaction, metaloxide electrical resistance is reset to the background level. During the measurement, when sensors are exposed to volatile compounds, the resistance of metal-oxide is changed due to the adsorption of volatile compound onto the metal-oxide surface, where it reacts with oxygen through oxidation/reduction. This change in electrical resistance is considered to be a response of the sensor to a particular sample (Albert et al., 2000; Ampuero and Bosset, 2003). MOS sensors respond to molecules like alcohols, ammonia, butane, carbon monoxide, chlorine, ethylene, heptane, hexane, hydrogen, hydrogen sulphide, methane, nitrogen dioxide, ozone, propane, sulphur dioxide and toluene (Cosio et al., 2006).

\section{Metal-oxide semiconductor field effect transistors (MOSFET)}

MOFSET sensors rely on the change of electrostatic potential. They consist of three parts: silicon semiconductor, silicon oxide insulator and catalytic metal "gate" (usually palladium, platinum, iridium or rhodium). During the interaction between polar molecules and the metal gate, the electric field gets to be modified, which results in voltage change. Gases detectable by MOFSET sensors include hydrogen, ammonia, ethanol, amines, acetone, hydrocarbons, carbon monoxide and nitrogen dioxide. MOS and MOFSET sensors differ in their processing conditions which ensure the detection of a wide range of different volatile compounds. In an electronic nose, MOFSET sensors operate through two arrays: one operating at $140{ }^{\circ} \mathrm{C}$ and the other operating at $170{ }^{\circ} \mathrm{C}$, that is to say, at the temperature much lower than with MOS sensors (which require the temperature of $400-500{ }^{\circ} \mathrm{C}$ during each process stage) (Cosio et al., 2006).

\section{Conducting organic polymer sensors (CP)}

Due to their exquisite transducer properties, polymers like polypyrole, polyaniline and polythiophene are widely used in sensor technology. Their conductivity potential thereby enables them to respond to various chemical and/or physical stimuli. When exposed to volatile molecules, a measurable change in their conductivity can be observed (Guadarrama et al., 2000). In this type of sensors, polymers are coated onto a ceramic substrate and seated between two gold-plated electrodes. The downside of polymer sensors is their high absorption of water vapour that decreases the number of binding sites available for other volatile compounds. This effect can be diminished by implementation of "filters", so as to hold water vapour or ethanol prior to analysis (Ampuero and Bosset, 2003).

\section{Piezoelectric sensors}

These types of sensors consist of a membranecoated piezoelectric quartz crystal and two gold electrodes that form an electric field. Adsorption of volatile molecules onto the surface of the membrane increases the mass of the device, resulting in the change of its resonance frequency (Ampuero and Bosset, 2003).

\section{Mass spectrometry-based sensors}

When it comes to food quality control, in the last few years mass spectrometry-based (MS) electronic noses have become an increasingly used alternative (or complement) to gas sensor-based electronic noses (Vinaixa et al., 2005). Mass detection-based e-noses use mass spectrometer as a sensor array. Upon injection, an MS pattern of the unresolved volatile compounds mixture is created. This means that each mass-to-charge ratio acts as a sensor. In this way, sensors detect any compound having a particular massto-charge ratio, so that MS-based electronic noses potentially have hundreds of sensors. A huge advantage of this kind of sensors is that they operate under well-known technology, with reproducibility, stability and sensitivity of mass spectrometers being long wellestablished (Ampuero and Bosset, 2003).

\section{Types and characteristics of taste sensors}

Same as with electronic noses, different sensing principles can be used with electronic tongues or 
taste sensors. A wide variety of chemical sensors can be employed into their design: electrochemical (potentiometric, voltammetric, impedimetric), optical or enzymatic sensors (biosensors). The use of electrochemical measurements for analytical purposes has found a vast range of applications. All commercially available systems are based on potentiometric measurements, especially Ion-Selective Electrodes (ISEs). Besides ISEs, Ion-Sensitive Field-Effect Transistors (ISFETs) are nowadays also gaining greater interest as sensors forming electronic tongue sensor arrays (Winquist et al., 2002; Ciosek and Wróblewski, 2011). The features of electronic tongue sensors are different from those of traditional chemical sensors: instead of high selectivity in substance detection, electronic tongue sensors have an overall selectivity that provides for global information on the analysed solution. That global information, later applied as a digital fingerprint of gustatory compounds, is analyzed using the appropriate pattern recognition tools (Wei et al., 2013).

\section{Potentiometry-based electronic tongue}

Potentiometry represents a direct application of the Nernst equation through the measurement of potentials of non-polarized electrodes lacking current flow. These potentials depend on the nature and concentration of ions present in the solution, as well as on the medium and the type of electrodes employed (Pioggia et al., 2007a). The equipment necessary for potentiometric studies includes an ionselective electrode, a reference electrode and a voltage-measuring device. Commonly used reference electrode is a silver/silver chloride $(\mathrm{Ag} / \mathrm{AgCl})$ electrode. The electrode consists of a silver wire coated with silver chloride placed into the chloride ions solution. A porous plug serves as a voltage bridge to the outer solution. An ion-selective electrode has a similar configuration, but makes use of an ion-selective membrane rather than a voltage bridge. This membrane should be non-porous, water insoluble and mechanically stable. It should have an affinity for the selected ion that is high and selective. Due to the binding of ions, a membrane potential will develop (Winquist et al., 2002).

A potentiometry-based electronic tongue was first presented by Toko and co-workers (Hayashi et al., 1990). It was composed of several kinds of lipid/ polymer membranes used for the transformation of taste quality information into an electric signal. The output of the system was not the amount of specific taste substances but rather the taste quality and intensity, because different output electric patterns are obtained for chemical substances producing different taste qualities (Hayashi et al., 1990; Toko, 1998). Another type of potentiometric electronic tongue was presented by Legin et al. (1996), configured by several non-specific sensors based on chalcogenide glasses as transducers.

Potentiometric electrodes are the most widely used sensors in electronic tongue systems. The sensing mechanism of the most of potentiometric sensors is based on a membrane made of inorganic (polycrystalline and chalcogenide glass) or organic (plasticized polymeric matrix doped with membrane active components, Langmuir-Blodgett or electropolymerised films, etc.) materials. The membrane is the main active component, but in the same time, also one of the sensor's weak points, because most drawbacks, such as reproducibility and long-term stability, depend on the membrane. Therefore, most of the research in this field is devoted to the development of suitable electrodes (Lvova et al., 2006; Pioggia et al., 2007a).

\section{Voltammetry-based electronic tongue}

In voltammetric techniques, a potential is applied on the working electrode, followed by the measurement of the resulting current between the working electrode and the reference electrode. As a result, an electrochemical redox reaction occurs at the electrodes' surface and gives rise to the measured current. All particles in the measured liquid, electrochemically active below the applied voltage, will contribute to the redox response (Iliev et al., 2006). The use of voltammetry as a sensing principle, under which an electronic tongue operates, appears to have several advantages; the technique is commonly used in analytical chemistry due to its very high sensitivity, versatility, simplicity and robustness. Besides, the technique offers the possibility of using and combining different analytical principles such as cyclic, stripping or pulsed voltammetry. Among various techniques, pulse voltammetry is of special interest due to its advantages in terms of greater sensitivity and resolution. Two types of pulse voltammetry are commonly used: large amplitude pulse voltammetry (LAPV) and small amplitude pulse voltammetry 


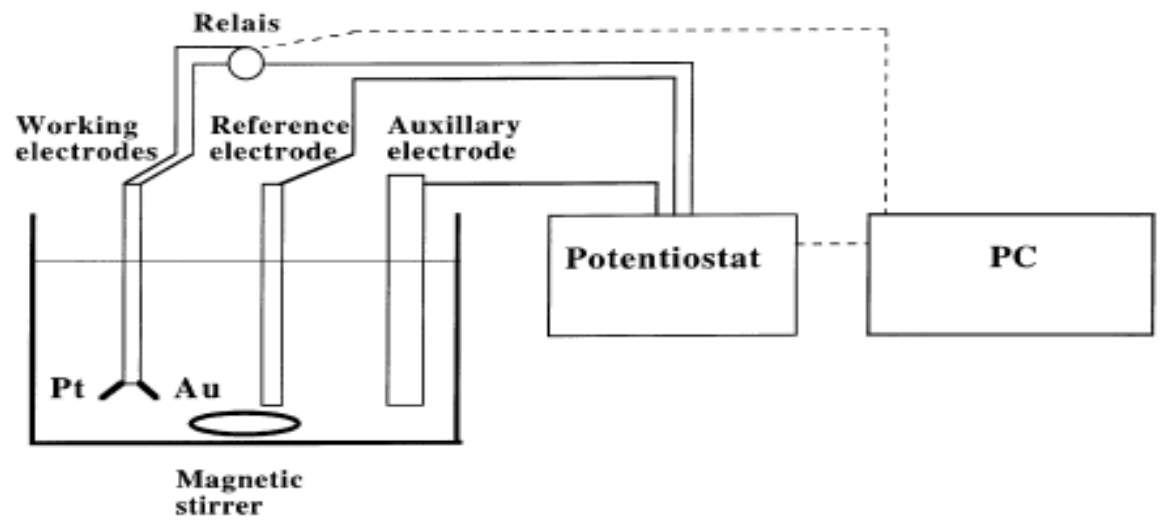

Measurement cell

Figure 3. Schematic diagram of the experimental set-up of the first voltammetry-based electronic tongue (Winquist et al., 1997)

(SAPV) (Winquist et al., 2002). Depending on the technique, various kinds or aspects of information can be obtained from the measured solution. A number of possibilities are available for obtaining information using voltammetry: choice of the potential applied (size, sweep rates, pulses etc.), type of working electrode or stripping techniques. When using voltammetry in complex media consisting of several redox-active compounds and various ions, the selectivity of the system is often insufficient for species analysis of single components, because the steps in the voltammogram are too close to be individually discriminated. Thus, rather complicated "spectra" are obtained and the interpretation of data may be difficult due to their complexity. Still, the voltammograms contain a large amount of information and to extract this, multivariate analysis methods have found increasing interest and use in the field (Winquist et al., 1997).

The first voltammetry-based electronic tongue was presented in 1997 by Winquist et al. (1997); the technique was chosen due to its high sensitivity, simplicity and robustness. The first sensor system had a three electrode-configuration with an $\mathrm{Ag} /$ $\mathrm{AgCl}$ reference electrode, a stainless steel counter electrode and two working electrodes made up of one platinum and one gold wire (Figure 3). Pulse voltammetry was used in order to obtain information on the diffusion coefficient of charged species (Winquist et al., 1997; Iliev et al., 2006).
Voltammetric electronic tongue has been further developed; the concept of voltammetric electronic tongue has been advanced throughout the recent years and proven valuable in many applications. Studies have shown that voltammetric electronic tongue could be used to monitor quality changes in milk (Winquist et al., 2002; Winquist et al., 2005; Wei et al., 2013).

\section{Impedance spectroscopy-based electronic tongue}

Recently, electrochemical impedance spectroscopy (EIS) has started to be employed into qualitative applications of electronic tongues (CortinaPuig et al., 2007). Impedance spectroscopy-based electronic tongue was first described by Riul et al. (2003). The sensors were constructed from pure and composite nano-structured films of conducting polymers. Impedance measurement is often used for preliminary characterization of complex circuits (Riul et al., 2003; Pioggia et al., 2007a; Pioggia et al., 2007b; Wei et al., 2013). In comparison with potentiometry and especially with voltammetry, impedance measurements are advantageous because of their simplicity and shorter response times (Cortina-Puig et al., 2007).

Almost all electronic tongues or taste sensors developed insofar are based on potentiometry or voltammetry. However, some other techniques such as optical techniques, enzymatic sensors (biosensors) 
or techniques based on mass-sensitive devices are also interesting to use; their special features make them useful for electronic tongues.

\section{An electronic tongue based on optical techniques}

Optical techniques are based on light absorption at specific wavelengths ranging from ultraviolet (UV) across the visible light to near infrared (NIR) and infrared (IR) spectrum. Many compounds have distinct absorption spectra, so that scanning at a certain wavelength may yield the spectrum specific to the tested sample. Optical methods offer advantages of high reproducibility and good long-term stability (Winquist et al., 2002).

\section{An electronic tongue based on biosensors}

Biosensors used with electronic tongues are systems equipped with a biochemical transducer, an enzyme and a solid electrode positioned in an intimate proximity. Enzymes are oxidases that consume oxygen and produce hydrogen peroxide or the reduced form of $\beta$-nicotinamide adenine dinucleotide (phosphate) (NAD(P)H) as a dehydrogenase. Improvement in performance of metal sensors, conductive polymers or biosensors, is linked to their downsizing to nano-dimensions, which increases the surface-tovolume ratio of the sensors, lowering thereby the detection limits (Baldwin et al., 2011).

\section{An electronic tongue based on mass-sensitive devices}

Mass sensitive devices based on piezoelectric crystals can also be useful. A quartz crystal resonator is operated at given frequency influenced by the absorption of certain compounds onto the crystal surface. As for a surface acoustic wave-based device, a surface wave propagates across the surface of the device. Due to the adsorption of compounds taking place underway, the properties of the surface wave can be changed. These types of devices give overall rather than specific information and can therefore be used to detect a number of different compounds (Winquist et al., 2002).

\section{Application of an electronic nose in dairy industry}

\section{Determination of milk quality and shelf-life}

In the recent years electronic noses have been successfully used in monitoring of the milk micro- bial count, its quality and shelf-life. Some bacteria capable of causing milk spoilage produce volatile compounds such as 3-methyl-1-butanol, ethyl butyrate, ethyl-3-metilbutanoat, ethyl hexanoate, acetaldehyde, acetic acid and ethanol, which can be used for an early detection of microbial milk spoilage and the differentiation of spoilage-causing microbial species. An electronic nose composed of 14 conducting polymer sensors is capable of discriminating between unspoiled milk and milk containing spoilage bacteria such as Bacillus cereus or Staphylococcus aureus, or yeasts like Klyveromyces lactis or Candida pseudotropicalis in different concentrations (Magan et al., 2001). Labreche et al. (2005) showed that measurements generated by an electronic nose can be used to detect bacteria growth in milk and to determine its shelf-life, and can therefore be used for milk freshness control. An electronic nose equipped with 18 metal oxide sensors was used in an analysis of volatile compounds present in milk during 52 days of storage at two temperatures: the ambient temperature and the temperature of $5{ }^{\circ} \mathrm{C}$. In parallel, total bacteria growth in milk was measured as well. Figures 4 and 5 show two extracted significant points (A-B) for the milk samples stored at the ambient temperature, which correspond to the significant changes in milk profile, and four significant points (A-D) for the milk samples stored at $5{ }^{\circ} \mathrm{C}$. Sensors' responses correspond to the significant changes in milk profile and are in correlation with the colony count (Labreche et al., 2005).

The results obtained by Capone et al. (2001) demonstrate the possibility of practical application of an electronic nose in dairy industry for the raw (starting) milk quality control and rancidity monitoring in different production stages. The authors showed the ability of a semiconductor thin filmsbased electronic nose to well distinguish UHT and pasteurised milk during days in which the milk has different rancidity values (Figures 6 and 7).

As mastitis is a disease that causes significant changes in milk composition and its volatile substance content, Eriksson et al. (2005) investigated into the possibility of using an electronic nose (equipped with MOS and MOFSET sensors) for the discrimination between the milk excreted from the mastitis-affected breast and the healthy one. The results were supported by the GC-MS analysis which identifies 103 volatile compounds. Mastitic milk 

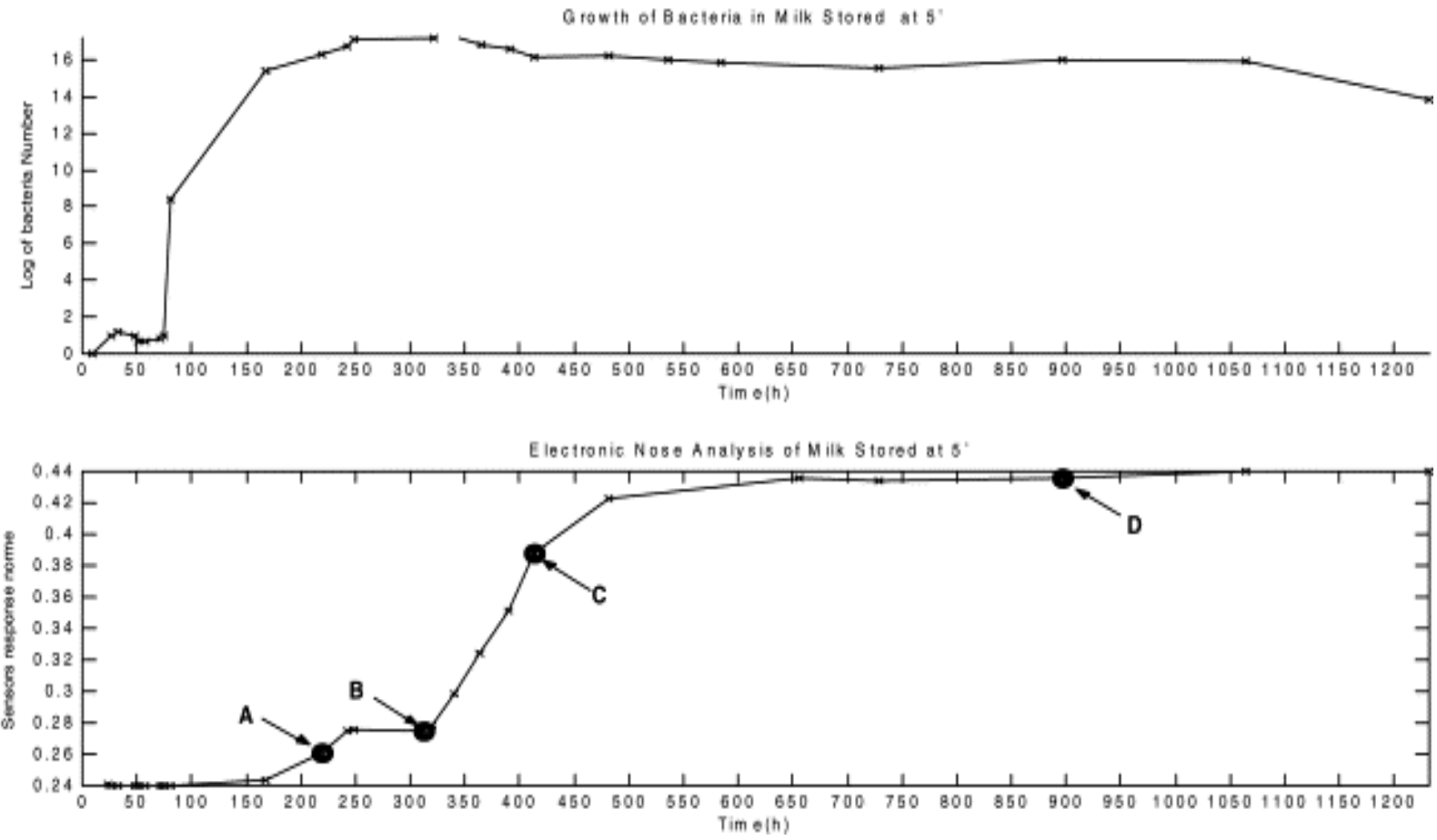

Figure 4. Correlation between bacterial growth and sensors' response descriptive of the milk samples stored at $5{ }^{\circ} \mathrm{C}$ (Labreche et al., 2005)
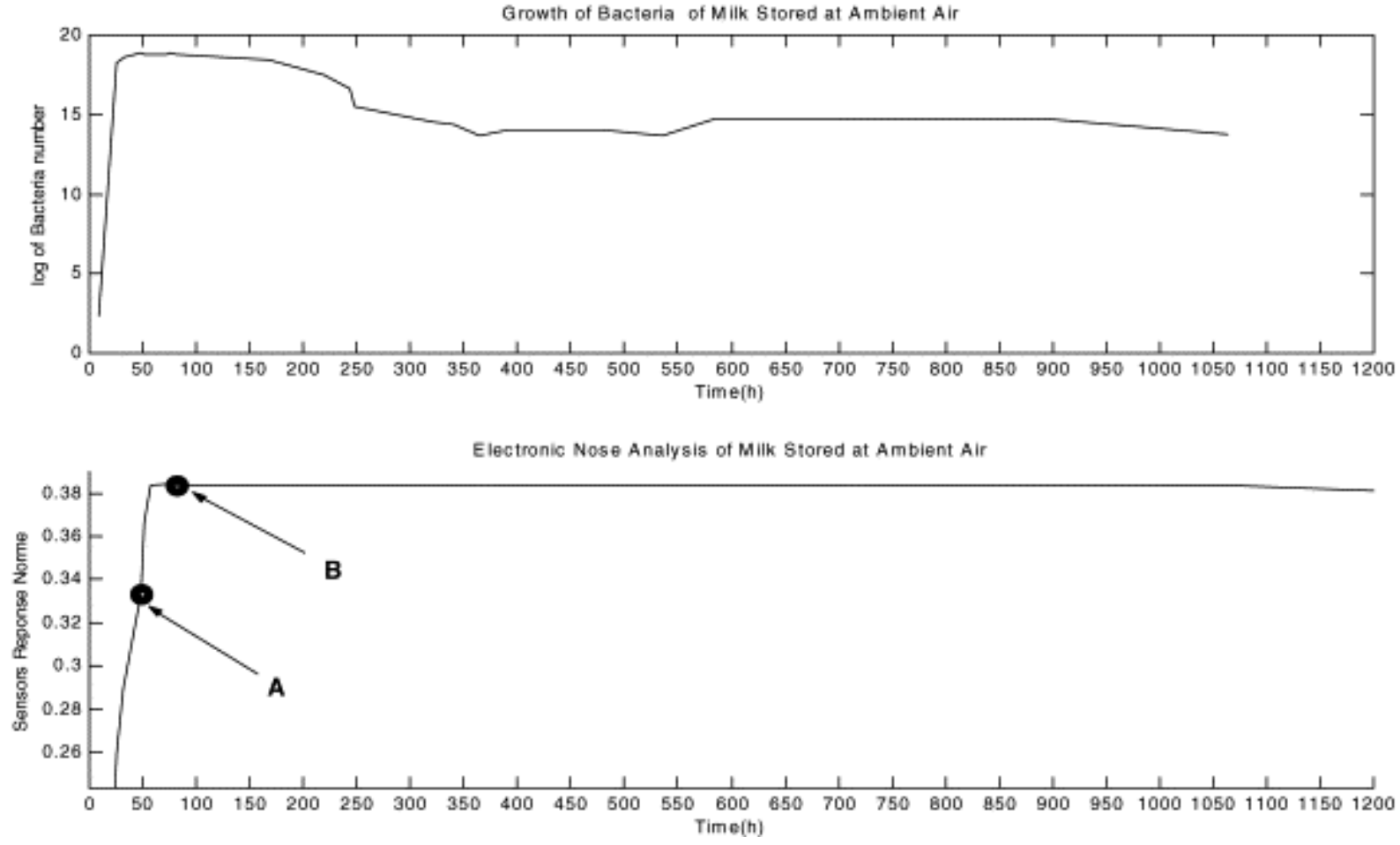

Figure 5. Correlation between bacterial growth and sensors' response descriptive of the milk samples stored at the ambient temperature (Labreche et al., 2005) 


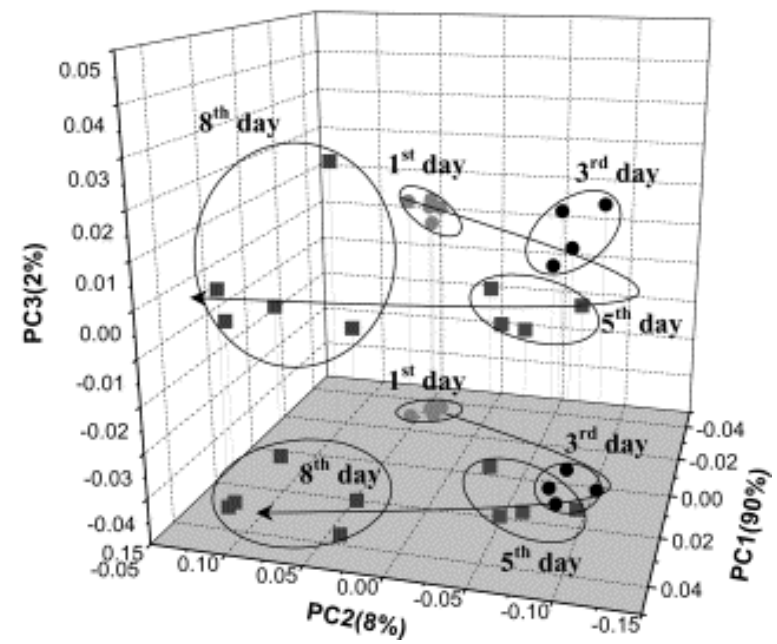

Figure 6. PCA plot of UHT milk on different days (Capone et al., 2001)

contained higher levels of sulphides, ketones, amines and acids.

Differentiation of cheeses - classification based on the cheese variety, its geographical origin, ripening stage and manufacturing procedure

O'Riordan and Delahunty (2003) showed that an electronic nose based on eight MOS sensors has the ability to discriminate cheeses of the same variety manufactured under standardised cheesemaking conditions, but using different starter cultures (bulk starter culture $v s$ commercial DVS starter culture). PCl, which accounted for $95 \%$ of differences between cheeses, grouped the majority of cheeses based on the type of starter culture used during manufacturing. Data obtained by an electronic nose were compared to the outcomes of cheese-graders assessment. The results showed an electronic nose to be capable of discriminating between various classes of cheese in a manner similar to that of a cheese-grader.

Gursoy et al. (2009) investigated into the possible use of an electronic nose (based on ion mobility spectrometry [IMS] and metal oxide sensors) for the discrimination of hard cheeses based either on their origin or their variety. Nine different Emmental cheese samples stemming from different countries (Germany, France, the Netherlands, Switzerland and Finland) were used to evaluate the potential of an electronic nose to discriminate between

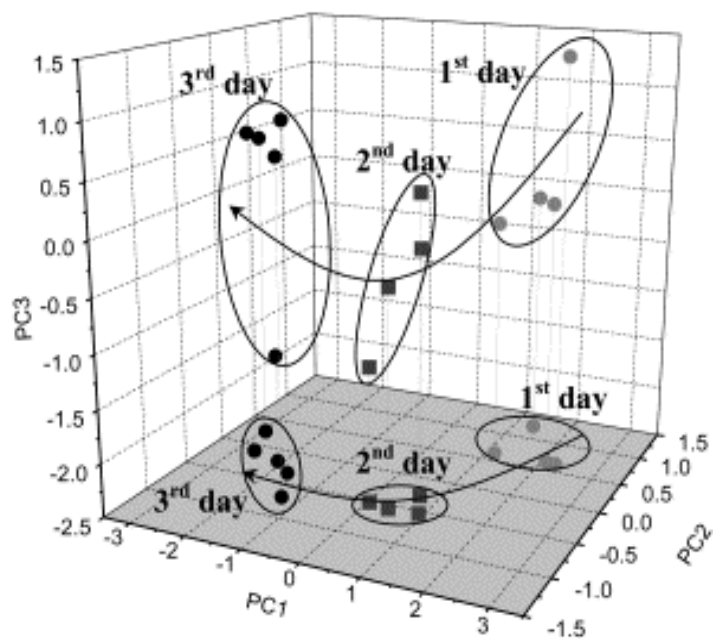

Figure 7. PCA plot of UHT milk on different days (Capone et al., 2001)

cheese samples based on their geographical origin. The results showed that such an e-nose is capable of clearly distinguishing between Emmental cheeses produced in different countries. It is known that Emmental cheese can be produced in more than one central European region, but Swiss Emmental cheese is definitely regarded as the most expensive. Such an electronic nose could be a rapid, simple and low-cost tool capable of checking for possible adulteration and therefore of verifying the authenticity of Swiss Emmental cheese. Within the frame of the same research, seven different cheese samples obtained from various markets in Finland, France or Belgium were used to attempt variety-based discrimination. These samples were of an extra-hard (Parmigiano Reggiano, Pecorino Romano, Grana and Grana Padano) and hard category (Old Master, Emmental and Gruyere). The results of PCA analysis of data provided by an e-nose indicated that the device is capable of clearly separating hard from extra-hard cheeses. As well as, a clear discrimination was obtained for cheese samples of Parmigiano Reggiano and Pecorino Romano, the first thereby being made of ewe and the second being made of cow milk. Grana (Finland) and Grana Padano (Italy) cheeses are both cow milk cheeses produced in a similar manner. Despite differences in their origin, their positions in the score plot were very close, which shows that these cheese varieties are of similar characteristics. 


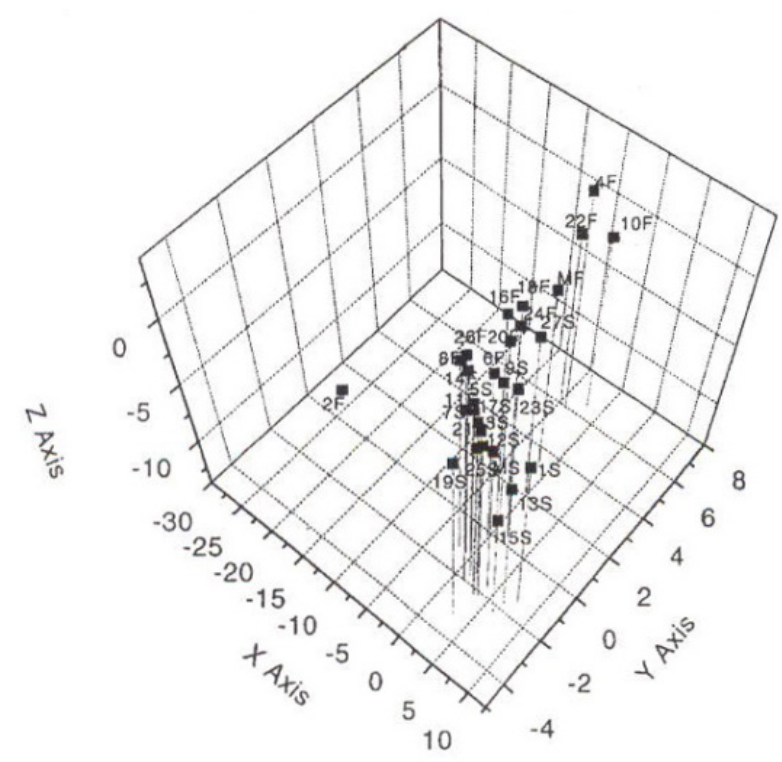

F - a 20 day-old cheese; S - a 4 month-old cheese

Figure 8. 3D-view of electronic nose sensor results for two types of Pecorino Toscano cheese (Contarini et al., 2001)

An electronic nose based on an array of six MOS sensors in combination with artificial neural network (ANN) can be very effective in classification of Pecorino cheeses (typical Italian Pecorino and "fossa" Pecorino cheeses) based on their ripening time and manufacturing techniques. The results of electronic nose analysis were compared to the results obtained by SPME-GC-MS analysis; the authors claimed the best results are to be obtained by e-nose signals' analysis. This could be explained by the fact that SPMEGC-MS can identify only individual chemical compounds, while an electronic nose can recognise even the combination of such compounds responsible for odour generation (Cevoli et al., 2011).

Upon monitoring the ripening process of 96 Danish blue cheeses during 12 weeks, Trihas et al. (2005) showed that an e-nose can be successful in determining the maturity of cheese. At the beginning (Day 0) and at the end of the ripening process (Week 12) cheeses can be very well differentiated by an electronic nose, but, contrast to that, after 2 and 4 weeks of the ripening the e-nose could not clearly separate between them due to their similar aroma profile, confirmed also by chemical analyses. In these ripening stages, volatile compounds and 4.6-pH soluble profiles are very similar.
Gursoy et al. (2009) investigated into the potential use of ion mobility spectrometry (IMS)-based and metal oxide sensor-based e-nose to discriminate Emmental cheeses of different ripening age. Twentyfour Emmental cheese samples of ripening ages of 3, 6 and 9 months were purchased from local markets in Finland. PCA score plot showed that cheeses ripened for 9 months can be clearly discriminated from those ripened for 3 or 6 months, leading also to the conclusion that the latter two cheese clusters are very similar when it comes to their volatile compound content. The results of the research of Contarini et al. (2001) showed that an electronic nose (based on conducting polymer sensors) is capable of not only distinguishing between the Pecorino Toscano cheeses of various ripening age (20 days $v s$ 4 months), but also of detecting samples having a higher concentration of contaminating bacteria. The sample (2F) which belongs to neither of the two groups (Figure 8) showed the same anomalous behaviour after a dynamic headspace analysis. The microbiological analysis showed this sample to have a content of contaminating bacteria higher than all other cheeses.

\section{Modelling of cheese ripening}

An electronic nose found its application in predicting the quality of cheese during ripening. Trihaas et al. (2005) analysed changes witnessed during a 12 week-ripening of the Danish blue cheese using commercial electronic nose which employs 12 MOS sensors. In parallel, chemical analyses (of volatile compounds, $\mathrm{pH} 4.6$ soluble peptides and free fatty acids) of the cheese samples were performed, those results later being used to indicate changes during maturation. E-nose measurements gave data suitable to model and predict chemical changes that are strongly related to the observed quality parameters. The results showed that an e-nose is very successful in predicting free fatty acid and $\mathrm{pH} 4.6$ soluble peptide contents, but unable to give a satisfactory prediction of volatile compound contents. The reasons behind such an outcome could be the fact that volatile compounds do not change linearly over time, since they are both produced and decomposed during the ripening period, as well as the fact that different cheese homogenization methods were used with e-nose employment 
and GC-MS analysis (Gonzales de Llano et al., 1990; Gallois and Langlois, 1990; Trihaas et al., 2005).

\section{Screening of aroma-producing lactic acid bacteria}

Consumer demands are constantly increasing, which requires the development of new types of cheeses. The formation of the typical cheese aroma comes as a result of complex biochemical reactions mediated mainly through cheese micro-flora. Therefore, the usage of different new cultures of lactic acid bacteria contributes to the innovativeness and attractiveness of cheese products. Classical molecular methods of bacterial strain classification have limited usage in selection of new lactic acid bacteria that will facilitate the development of better and more attractive cheese aroma, since they give no indication of the capacity to produce flavour compounds. Marilley et al. (2004) showed that MS-based electronic nose system can be very efficient in discriminating closely related strains and different bacterial species based on their production of volatile compounds. Strains of the same genotype were grouped together in conformity with the classification obtained by the Polymerase Chain Reaction (PCR) molecular method. In contrast to other electronic noses, which only detect changes in physical properties of gas sensors, MS-based electronic sensors generate a mass spectrum and therefore can be used to screen for new aroma-producing strains.

As Lactococcus lactis are widely spread in nature and represent the lactic acid bacteria most commonly used in cheese production, GutiérrezMéndez et al. (2008) screened for aroma generated by Lactococcus lactis strains isolated from different sources, so as to explore the possibility of their use in starter cheese cultures. To that goal, an electronic nose equipped with 12 MOS sensors was employed. Lactococcus lactis strains showed clear phenotypic differences (lactose fermentation, proteolytic activity and citrate utilization) related to their isolation source, but no clear relationship between the source of isolation (dairy source, non-dairy source and industrial starter culture) and aroma-producing ability. Additionally, an aroma-potentiating effect was observed when mixtures of two Lactococci strains isolated from different sources acted together, which could be explained by the cooperation between their metabolic pathways.

\section{Application of an electronic tongue in dairy industry}

\section{Classification of samples}

The main purpose of electronic tongues is qualitative analysis, and thus several works on the application of electronic tongue devices in recognition, classification or identification of milk and fermented milk samples have been reported. In an experiment attempted to the goal of fermented milk samples' classification, a hybrid electronic tongue based on voltammetric, potentiometric and conductometric measurements was used. The hybrid tongue separated all six samples analysed, while the nature of micro-organisms in different fermentations reflected in the PCA. The measurement situation was enlightened from different positions and by combining information from different origins, an additional dimension of information was added showing the great importance of the system in many fields (Winquist et al., 2000). Winquist et al. (2005) used a specially designed voltammetric electronic tongue inserted directly on-line in dairy industry process line. The results of the study showed that milk from different sources and thus also of different quality, can be mutually separated. Thus, the possibility of monitoring off-flavours in the incoming milk was opened, indicating that an electronic tongue could be a valuable security measure to prevent economic loss suffered due to the contamination of a large volume of raw milk with off-flavour milk entering a storage silo in the dairy plant (Winquist et al., 2005). Ciosek and Wróblewski (2008) presented the application of a new construction of potentiometric electronic tongue based on an integrated microelectrode sensor array intended for the classification of milk originating from various producers. An integrated array of microelectrodes was fabricated from epoxy glass laminate. PVC membranes coated with various additives were used as chemo-sensitive layers. The system exhibited satisfactory classification abilities towards milks originating from various dairies. Moreover, the comparison of milk classification results obtained with the use of commercial $\mathrm{Ag} / \mathrm{AgCl}$ electrode and miniaturized reference electrode based on ionic liquid (1-dodecyl-3-methyl-imidazolium chloride) showed that a miniature reference electrode can be integrated with ion-selective electrodes on the same substrate, which can be advantageous for future constructions and applications of potentiometric 
electronic tongues. The presented integrated microelectrode array can form the base of a handheld electronic tongue (Ciosek and Wróblewski, 2008). Hruškar et al. (2010a) emphasized the usefulness of potentiometric sensor array in the classification of different types of probiotic fermented milk during the entire shelf-life. The sensor array successfully reported changes in composition that occurred during the storage of probiotic fermented milk and was capable of tracking different rates of degradation of such milk stored at two different temperatures. Measurements done by potentiometric sensor array achieved a high correlation with the results of human sensory panel (Hruškar et al., 2010a).

\section{Determination of compounds responsible for aroma development}

Complex data sets from electronic tongue signals and standard analytical measurements employing prediction models have been used for the prediction of different compounds' concentrations. Hruškar et al. (2010b) evaluated the performance of potentiometry-based electronic tongue in rapid determination of compounds responsible for aroma development in probiotic fermented milk such are ethanol, acetaldehyde, diacetyl, lactic acid, acetic acid and citric acid. Different types of probiotic fermented milk samples were analysed both using standard analytical methods and an electronic tongue. ANN models were used for rapid estimation of aroma compounds' content in probiotic fermented milk samples. The best prediction capability with a low error of prediction was obtained with the estimation of ethanol content. Good prediction capability with slightly higher prediction errors was exhibited by ANN models suitable for acetic acid, citric acid, lactic acid and diacetyl concentration determination. Only the model intended for acetaldehyde determination exhibited low accuracy of prediction. The obtained results indicate that potentiometric electronic tongues coupled with ANN models can be applied as a rapid method of determination of aroma compounds in probiotic fermented milk (Hruškar et al., 2010b).

\section{Microbial quality}

The electronic tongue has been used in monitoring of microbial properties of milk that makes use of prediction models and pattern recognition techniques employed to the goal of bacterial count determination. Winquist et al. (1998) described an electronic tongue measurement principle based on pulsed voltammetry, in which successive voltage pulses of gradually changing amplitudes were applied to the working electrodes connected in a standard three-electrode configuration. An electronic tongue was used to follow the deterioration of quality of the milk stored at the room temperature, arising on the grounds of microbial growth. The obtained data were subject to PCA, while the deterioration process could be clearly followed in the diagrams. To compile prediction models, projections to the latent structure and ANN were used, both of them being proven to satisfactorily predict the course of bacterial growth in milk samples (Winquist et al., 1998). Wei et al. (2013) used self-developed voltammetric electronic tongue based on multi-frequency rectangle pulse voltammetry (MRPV) and multi-frequency staircase pulse voltammetry (MSPV) to monitor the storage time of unsealed pasteurized milk and to explore the relation between physicochemical and microbiological properties of the pasteurized milk and voltammetric data gathered during storage. The unsealed pasteurized milk samples were measured at seven different time points spread over $72 \mathrm{~h}$, and classified using two pattern recognition techniques, i.e. PCA and cluster analysis (CA). Additionally, total bacterial count, acidity and viscosity were analyzed immediately after voltammetric electronic tongue experiments, employing two pattern recognition techniques (PLSR and LS-SVM) for total bacterial count and viscosity forecast. The milk samples stored for a different length of time were clearly classified using a voltammetric electronic tongue based on MRPV and MSPV (Figure 9). PLSR and LS-SVM showed high correlation between the measured and the predicted values both when it comes to viscosity and prediction of total bacterial count (Wei et al., 2013).

\section{Mastitis detection}

Mottram et al. (2007) conducted an experiment so as to determine whether an electronic tongue multi-sensor system based on potentiometric chemical sensors and suitable data processing could be used to discriminate between milk secretions from infected and healthy glands. It was demonstrated that a multi-sensor system can distinguish between the control and clinically mastitic milk samples (a total 
of 67 samples of milk excreted by either mastiticor healthy glands). The results showed that a multisensor system offers a novel method for mastitis detection and discrimination between milk samples coming from cows suffering from clinical mastitis and those coming from healthy animals. An array of fifteen chemical sensors (an electronic tongue) proved itself as the best detection method above an array of three ion-selective electrodes and conductivity (Mottram et al., 2007).

\section{Determination of antibiotic residues}

The concept of application of electronic tongue data sets together with pattern recognition techniques for predictions of different compounds' concentration have been used for predictions of antibiotic residues in milk. A voltammetric electronic tongue used for the detection of antibiotic residues in bovine milk was developed by Wei and Wang (2011). A possible model of antibiotics' category and prediction sorting at different concentration levels based on voltammetric electronic tongue was explored. Six antibiotics (Chloramphenicol, Erythromycin, Kanamycin sulphate, Neomycin sulphate, Streptomycin sulphate and Tetracycline $\mathrm{HCl}$ ), present at four concentration levels (0.5-, 1-, 1.5- and 2- maximum residue limits (MRLs)), were measured using a voltammetric electronic tongue, while the obtained response signals were analysed using four pattern recognition techniques: PCA, DFA, PLS regression and least squaressupport vector machines (LS-SVM). The voltammetric electronic tongue was composed of five working electrodes (gold, silver, platinum, palladium, and titanium) positioned in a standard three-electrode configuration. Multi-frequency large amplitude pulse voltammetry (MLAPV) consisting of four segments $(1 \mathrm{~Hz}, 10 \mathrm{~Hz}, 100 \mathrm{~Hz}$ and 1,000 Hz) was applied as a potential waveform. At the MRLs, the six antibiotics could not be completely separated from bovine milk
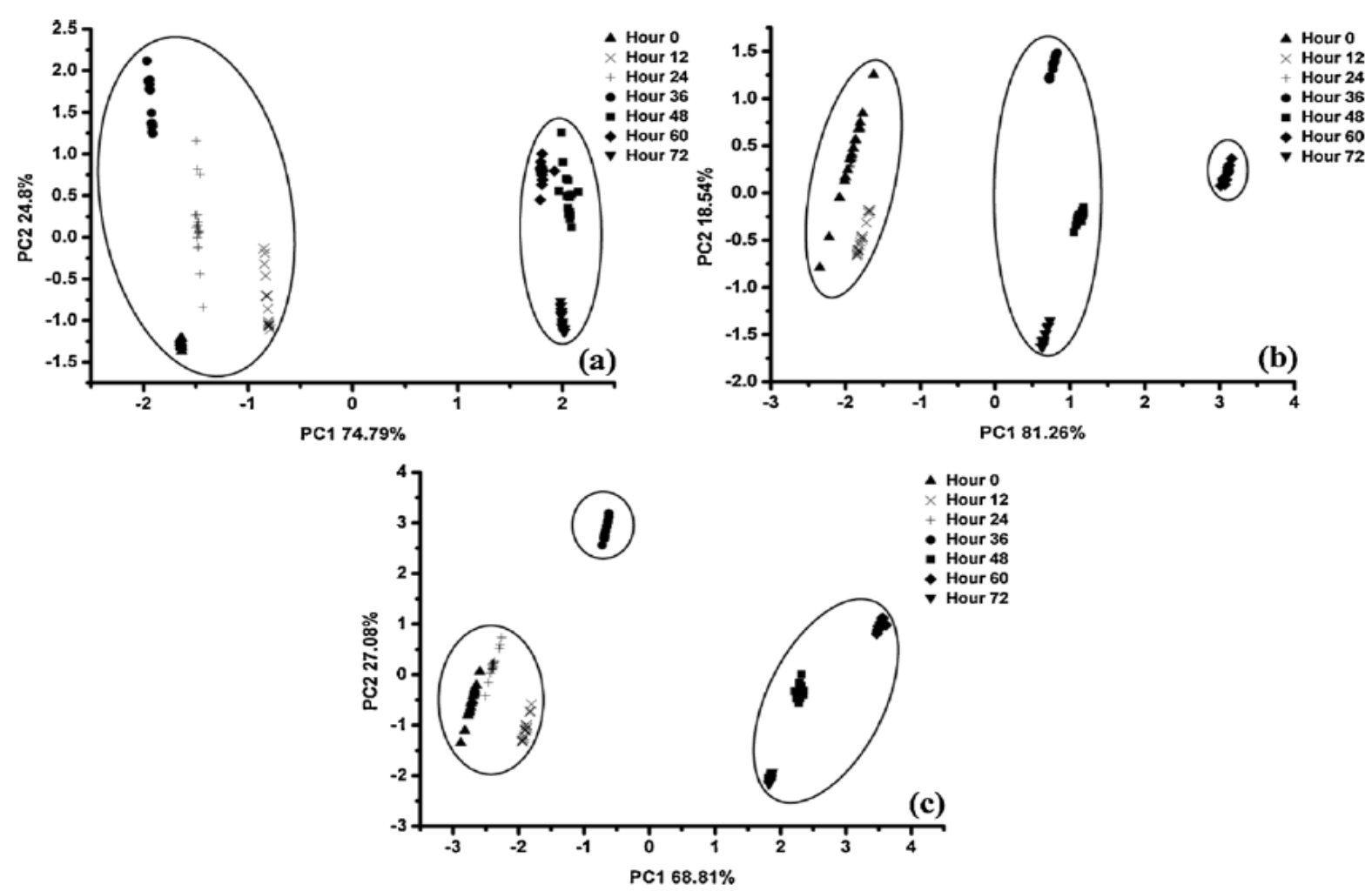

Figure 9. PCA score plots of data obtained for milk samples in different storage periods using a MRPVand MSPV-based voltammetric electronic tongue. (a) MRPV-based outcomes, (b) MSPVbased outcomes, (c) outcomes yielded by the combination of MRPV- and MSPV-based data (Wei et al., 2013) 
using PCA, but were clearly demarcated by DFA. Three regression models - PCR, PLSR, and LS-SVM - were used for the prediction of antibiotic concentrations; all the regression models performed well, PCR thereby having the most stable results (Wei and Wang, 2011).

\section{Milk adulteration}

There is an open field for the development of sensors to be used for the characterization of milk adulteration. Dias et al. (2009) constructed an allsolid-state potentiometric electronic tongue with two units of 20 polymeric membranes each (18 different and 2 selected membranes' replicates), working in parallel, in which the polymeric mixtures were applied on solid conducting silver-epoxy supports to use the taste recognition ability of the electronic tongue to detect raw goat milk adulterations with raw cow milk by means of LDA. The results showed that a multi-sensor device applied to study caprine milk adulterations with bovine milk, which poses a problem in the dairy industry, was able to give different signal profiles associated with specific sensory characteristics of each skimmed milk sample, allowing the discrimination between goat, cow and goat/ cow raw skimmed milks with satisfactory sensibilities and specificities. The authors showed that this methodology can be used as a fast and economic procedure to evaluate possible adulterations of goat raw milk with cow raw milk in a real timeframe (Dias et al., 2009). Paixăo and Bertotti (2009) constructed a disposable electronic tongue with gold CD-R and copper sheet substrates and golden sensing elements, the copper and gold surface thereby being modified with a Prussian Blue layer. The performance, the electrode materials and the capability of the device to differentiate samples were evaluated using a taste substances model, that is to say, milk obtained using different pasteurization processes (homogenized/pasteurized, ultra high temperature (UHT)pasteurized and low fat content UHT-pasteurized milk) and adulterated with hydrogen peroxide. In all analysed cases, a good separation between different samples was noticed in PCA score plots. The authors highlighted the importance of fabrication of disposable sensors in the particular case of milk analysis, because high contents of organic materials which adsorb onto the electrode surface may change the voltammetric response (Paixăo and Bertotti, 2009).

\section{Conclusion}

Although human olfactory and taste systems and sensory assessment of food cannot be replaced by any device, numerous works have shown that electronic nose and electronic tongue pose as excellent non-destructive methods for the determination of volatile and non-volatile food compounds. Their wide application can be found in food industry, where they can be employed into the identification and classification of products, monitoring of the ripening process (especially in cheese industry) and determination of the optimal ripening time (especially when it comes to fruit), monitoring of food spoilage (milk spoilage determination thereby presenting a showcase), food shelf-life determination and food adulteration detection. Their major advantage is the possibility of continuous monitoring of product quality from the very beginning (i.e. from the field) across all processing stages down to the final product. Compared with the electronic nose and electronic tongue, classical instrumental analysis employed for the determination of volatile and non-volatile compounds (i.e. chromatography) is much more expensive and time-consuming. Electronic nose and electronic tongue can be calibrated to be reliably consistent and can give objective data for quality and safety control. These instruments can also test samples unfit for human consumption. Although the electronic nose and electronic tongue are considered to be a revolutionary discovery in the field of sensory evaluation, some shortfalls are still witnessed. A disadvantage of electronic nose and electronic tongue systems is that they are affected by environmental conditions including temperature (both electronic nose and electronic tongue) and moisture (electronic nose), which can cause sensor drift, although calibration systems and built-in algorithms help compensate for this. In addition, it is necessary to conduct a more extensive research so as to come up with the type of sensors best fit for the detection of a particular type of volatile and taste components of certain dairy products, as well as with the best statistical method for processing of data obtained by an electronic nose and electronic tongue, so as to refine their practical applications in the dairy industry to a reliable level. From an instrumental point of view, it would be interesting to combine an electronic nose and an electronic tongue to obtain complementary information on the same sample by means of a hybrid array. 


\section{Primjena elektronskog nosa i elektronskog jezika u mljekarskoj industriji}

\section{Sažetak}

Elektronski nos i elektronski jezik predstavljaju instrumentalne sustave konstruirane $\mathrm{u}$ svrhu reprodukcije olfaktornog i okusnog senzorskog sustava čovjeka, a čiju osnovu čini niz senzora. Kompleksni podaci signala elektronskog nosa i elektronskog jezika, upotpunjeni multivarijantnim statističkim metodama omogućuju brze i učinkovite metode klasifikacije, razlikovanja, prepoznavanja i identifikacije uzoraka a također i predviđanja koncentracija različitih sastojaka. Široki spektar različitih senzora može biti uključen $u$ izvedbu navedenih instrumentalnih sustava, osobito u slučaju elektronskog jezika, omogućujući brojne praktične primjene. U ovom radu dan je pregled karakteristika senzora i mogućnosti primjene elektronskog nosa i elektronskog jezika u mljekarskoj industriji.

Ključne riječi: elektronski nos, elektronski jezik, mljekarska industrija, klasifikacija, razlikovanje

\section{References}

1. Albert, K.J., Lewis, N.S., Schauer, C.L., Sotzing, G.A., Stitzel, S.E., Vaid, T.P., Walt, D.R. (2000): Cross-reactive chemicalsensorarrays. ChemicalReviews 100,2595-2626. doi: dx.doi.org/10.1021/cr980102w

2. Ampuero, S., Bosset, J.O. (2003): The electronic nose applied to dairy products: a review. Sensors and Actuators B 94, 1-12. doi: dx.doi.org/10.1016/S0925-4005(03)00321-6

3. Bakker, J. (1997) Sensory evaluation of dairy flavours. In: Microbiology and biochemistry of cheese and fermented milk, 2. izd. (Law, B.A., ed.), Blackie Academic and Professional, London, 341-362. doi: dx.doi.org/10.1007/978-1-4613-1121-8_11

4. Baldwin, E.A., Bai, J., Plotto, A., Dea, S. (2011): Electronic noses and tongues: Applications for the food and pharmaceutical industries, Sensors 11, 4744-4766. doi: dx.doi.org/10.3390/s1 10504744

5. Biolatto, A., Grigioni, G., Irurueta, M., Sancho, A.M., Taverna, M., Pensel, N. (2007): Seasonal variation in the odour characteristics of whole milk powder. Food Chemistry 103, 960-967. doi: dx.doi.org/10.1016/j.foodchem.2006.09.050
6. Cabezas, L., Sánchez, I., Poveda, J.M., Sesena, S., Palop, M.L.L. (2007): Comparison of microflora, chemical and sensory characteristics of artisanal Manchego cheeses from two dairies. Food Control 18, 11-17. doi: dx.doi.org/10.1016/j.foodcont.2005.07.010

7. Capone, S., Epifani, M., Quaranta, F., Siciliano, P., Taurino, A., Vasanelli, L. (2001): Monitoring of rancidity of milk by means of an elektronic nose and a dynamic PCA analysis. Sensors and Actuators B 78, 174-179. doi: dx.doi.org/10.1016/S0925-4005(01)00809-7

8. Cevoli, C., Cerretani, L., Gori, A., Caboni, M.F., Gallina Toschi, T., Fabbri, A. (2011): Classification of Pecorino cheeses using electronic nose combined with artificial neural network and comparison with GC-MS analysis of volatile compounds. Food Chemistry 129 (3), 1315-1319. doi: dx.doi.org/10.1016/j.foodchem.2011.05.126

9. Cerrato Oliveros, M.C., Perez Pavon, J.L., Garca Pinto, C., Fernandez Laespada, M.E., Moreno Cordero, B., Forina, M. (2002): Electronic nose based on metal oxide semiconductor sensors as a fast alternative for the detection of adulteration of virgin olive oils. Analytica Chimica Acta 459, 219-228. doi: dx.doi.org/10.1016/S0003-2670(02)00119-8

10. Ciosek, P., Wróblewski, W. (2008): Miniaturized electronic tongue with an integrated reference microelectrode for the recognition of milk samples, Talanta 76, 548-556. doi: dx.doi.org/10.1016/j.talanta.2008.03.051

11. Ciosek, P., Wróblewski, W. (2011): Potentiometric electronic tongues for foodstuff and biosample recognition-an overview. Sensors 11, 4688-4701. doi: dx.doi.org/10.3390/s1 10504688

12. Contarini, G., Povolo, M., Toppino, P.M., Radovic, B., Lipp, M., Anklam, E. (2001): Comparison of three different techniques for the discrimination of cheese: application to the ewe's cheese. Milchwissenschaft 56 (3), 136-140.

13. Cortina-Puig, M., Muñoz-Berbel, X., Alonso-Lomillo, M.A., Muñoz-Pascual, F.J., del Valle, M. (2007): EIS multianalyte sensing with an automated SIA system-An electronic tongue employing the impedimetric signal. Talanta 72, 774-779. doi: dx.doi.org/10.1016/j.talanta.2006.12.016

14. Cosio, M.S., Ballabio, D., Benedetti, S., Gigliotti, C. (2006): Geographical origin and authentication of extra virgin olive oils by an electronic nose in combination with artificial neural networks. Analytica Chimica Acta 567, 202-210. doi: dx.doi.org/10.1016/j.aca.2006.03.035

15. Deisingh, A.K., Stone, D.C., Thompson, M. (2004): Applications of electronic noses and tongues in food analysis. International Journal of Food Science and Technology 39, 587-604. doi: dx.doi.org/10.1111/j.1365-2621.2004.00821.x

16. Dias, L.A., Peres, A.M., Veloso, A.C.A., Reis, F.S., VilasBoas, M., Machado, A.A.S.C. (2009): An electronictongue taste evaluation: Identification of goat milk adulteration with bovine milk. Sensors and Actuators B 136, 209-217. doi: dx.doi.org/10.1016/j.snb.2008.09.025 
17. Eriksson, A., Persson Waller, K., Svennersten-Sjaunja, K., Haugen, J-E., Lundby, F., Lind, O. (2005): Detection of mastitic milk using a gas-sensor array system (electronic nose). International Dairy Journal 15, 1193-1201. doi: dx.doi.org/10.1016/j.idairyj.2004.12.012

18. Gallois, A., Langlois, D. (1990): New results in the volatile odorous compounds of French cheeses. Le Lait 70, 89-106. doi: dx.doi.org/10.1051/lait:199028

19. Giese, J. (2000): Electronic noses. Food Technology 54 (3), 96-98.

20. Gomez, A.H., Wang, J., Hu, G., Pereira, A.G. (2006): Electronic nose technique potential monitoring mandarin maturity. Sensors and Actuators B 113, 347-353. doi: dx.doi.org/10.1016/j.snb.2005.03.090

21. Gomez, A.H., Wang, J., Hu, G., Pereira, A.G. (2007): Discrimination of storage shelf-life for mandarin by electronic nose technique, LWT 40, 681-689. doi: dx.doi.org/10.1016/j.lwt.2006.03.010

22. Gomez, A.H., Wang, J., Hu, G., Pereira, A.G. (2008): Monitoring storage shelf life of tomato using electronic nose technique. Journal of Food Engineering 85, 625-631. doi: dx.doi.org/10.1016/j.jfoodeng.2007.06.039

23. Gonzalez de Llano, D., Ramos, M., Polo, C., Sanz, J., Martinez-Castro, I. (1990): Evolution of the volatile components of an artisanal Blue cheese during ripening, Journal of Dairy Science 73, 1676-1683. doi: dx.doi.org/10.3168/jds.S0022-0302(90)78842-X

24. Gostelow, P., Parsons, S.A., Stuetz, R.M. (2001): Odour measurements for sewage treatment works. Water Research 35 (3), 579-597. doi: dx.doi.org/10.1016/S0043-1354(00)00313-4

25. Guadarrama, A., Rodriguez-Mendez, M.L., de Saja, J.A., Rios, J.L., Olias, J.M. (2000): Array of sensors based on conducting polymers for the quality control of the aroma of the virgin olive oil. Sensors an Actuators B 69, 276-282. doi: dx.doi.org/10.1016/S0925-4005(00)00507-4

26. Gursoy, O., Somervuo, P., Alatossava, T. (2009): Preliminary study of ion mobility based electronic nose MGD-1 for discrimination of hard cheeses. Journal of Food Engineering 92 (2), 202-207. doi: dx.doi.org/10.1016/j.jfoodeng.2008.11.002

27. Gutiérrez-Méndez, N., Vallejo-Cordoba, B., GonzálezCórdova, A.F., Nevárez-Moorillón, G. V., RiveraChavira, B. (2008): Evaluation of Aroma Generation of Lactococcus lactis with an Electronic Nose and Sensory Analysis. Journal of Dairy Science 91, 49-57. doi: dx.doi.org/10.3168/jds.2007-0193

28. Hayashi, K., Yamanaka, M., Toko, K., Yamafuji, K. (1990): Multichannel taste sensor using lipid membranes. Sensors and Actuators B: Chemical 2 (3), 205-213. doi: dx.doi.org/10.1016/0925-4005(90)85006-K

29. Hodgins, D. (1997): The electronic nose: Sensor arraybased instruments that emulate the human nose. In: Techniques for Analysing Food Aroma (R. Marsili, ed.), Marcel Dekker Inc., New York, 331-371.

30. Hruškar, M., Major, N., Krpan, M. (2010a): Application of a potentiometric sensor array as a technique in sensory analysis. Talanta 81, 398-403. doi: dx.doi.org/10.1016/j.talanta.2009.12.015
31. Hruškar, M., Major, N., Krpan, M., Vahčić, N. (2010b): Simultaneous determination of fermented milk aroma compounds by a potentiometric sensor array. Talanta 82, 1292-1297. doi: dx.doi.org/10.1016/j.talanta.2010.06.048

32. Iliev, B., Lindquist, M., Robertsson, L., Wide, P. (2006): A fuzzy technique for food-and water quality assessment with an electronic tongue. Fuzzy Sets and Systems 157, 1155-1168. doi: dx.doi.org/10.1016/j.fss.2005.12.014

33. Labreche, S., Bazzo, S., Cade, S., Chaine, E. (2005.): Shelf life detrmination by electronic nose: application to milk. Sensors and Actuators B 106, 199-206. doi: dx.doi.org/10.1016/j.snb.2004.06.027

34. Legin, A.V., Vlasov, Y.G., Rudnitskaya, A.M., Bychkov, E.A. (1996): Cross-sensitivity of chalcogenide glass sensors in solutions of heavy metal ions. Sensors and Actuators B 34, 456-461. doi: dx.doi.org/10.1016/S0925-4005(96)01852-7

35. Lvova, L., Martinelli, E., Mazzone, E., Pede, A., Paolesse, R., Di Natale, C., D' Amico, A. (2006): Electronic tongue based on an array of metallic potentiometric sensors. Talanta 70, 833-839. doi: dx.doi.org/10.1016/j.talanta.2006.02.014

36. Magan, N., Pavlou, A., Chrysanthakis, I. (2001): Milksense: avolatile sensing system recognise spoilage bacteria and yeasts in milk. Sensors and Actuators B, 28-34. doi: dx.doi.org/10.1016/S0925-4005(00)00621-3

37. Marilley, L., Ampuero, S., Zesiger, T., Casey, M.G. (2004): Screening of aroma-producing lactic acid bacteria with an electronic nose. International Dairy Journal 14, 849-856. doi: dx.doi.org/10.1016/j.idairyj.2004.02.013

38. Mottram, T., Rudnitskaya, A., Legin, A., Fitzpatrick, J.L., Eckersall, P.D. (2007): Evaluation of a novel chemical sensor system to detect clinical mastitis in bovine milk. Biosensors and Bioelectronics 22, 2689-2693. doi: dx.doi.org/10.1016/j.bios.2006.11.006

39. O’Riordan, J.P., Delahunty, C.M. (2003): Characterisation of commercial Cheddar cheese flavour. 1: traditional and electronic nose approach to quality assesment and market classification. International Dairy Journal 13, 355-370. doi: dx.doi.org/10.1016/S0958-6946(03)00005-0

40. Paixăo, T.R.L.C., Bertotti, M. (2009): Fabrication of disposable voltammetric electronic tongues by using Prussian Blue films electrodeposited onto CD-R gold surfaces and recognition of milk adulteration. Sensors and Actuators B 137, 266-273. doi: dx.doi.org/10.1016/j.snb.2008.10.045

41. Piggot, J.R. (1994): Understanding flavour quality: diffcult or impossible? Food Quality and Preference 5 (1-2), 167-171. doi: dx.doi.org/10.1016/0950-3293(94)90024-8

42. Pioggia, G., Di Francesco, F., Marchetti, A., Ferro, M., Ahluwalia, A. (2007a): A composite sensor array impedentiometric electronic tongue Part I. Characterization. Biosensors and Bioelectronics 22, 2618-2623. doi: dx.doi.org/10.1016/j.bios.2006.10.031 
43. Pioggia, G., Di Francesco, F., Marchetti, A., Ferro, M., Leardi, R., Ahluwalia, A. (2007b): A composite sensor array impedentiometric electronic tongue Part II. Discrimination of basic tastes. Biosensors and Bioelectronics 22, 2624-2628. doi: dx.doi.org/10.1016/j.bios.2006.10.025

44. Riul, A., Malmegrim, R.R., Fonseca, F.J., Mattoso, L.H.C. (2003): An artificial taste sensor based on conducting polymers. Biosensors and Bioelectronics 18, 1365-1369. doi: dx.doi.org/10.1016/S0956-5663(03)00069-1

45. Santonico, M., Pittia, P., Pennazza, G., Martinelli, E., Bernabei, M., Paolesse, R., D’Amico, A., Compagnone, D., DiNatale, C. (2008): Study of the aroma of artificially flavoured custards by chemical sensor array fingerprinting. Sensors and Actuators B 133, 345-351. doi: dx.doi.org/10.1016/j.snb.2008.02.053

46. Tian, S.-Y., Deng, S.-P., Chen,Z.-X. (2007): Multifrequency large amplitude pulse voltammetry: A novel electrochemical method for electronic tongue. Sensors and Actuators B 123, 1049-1056. doi: dx.doi.org/10.1016/j.snb.2006.11.011

47. Toko, K. (1998): Electronic tongue, Biosensors and Bioelectronics 13, 701-709. doi: dx.doi.org/10.1016/S0956-5663(98)00025-6

48. Trihaas, J., Vognsen, L., Nielsen, P.V. (2005): Electronic nose: New tool in modelling the ripening of Danish blue cheese. International Dairy Journal 15, 679-691. doi: dx.doi.org/10.1016/j.idairyj.2004.07.023

49. Turner, A.P.F., Magan, N. (2004): Electronic noses and disease diagnostics. Nature Reviews Microbiology2, 161-166. doi: dx.doi.org/10.1038/nrmicro823

50. Vinaixaa, M., Vergaraa, A., Durana, C., Llobeta, E., Badiab, C., Brezmesa, J., Vilanovaa, X., Correiga, X. (2005) Fast detection of rancidity in potato crisps using e-noses based on mass spectrometry or gas sensors. Sensors and Actuators B: Chemical 106 (1), 67-75. doi: dx.doi.org/10.1016/j.snb.2004.05.038
51. Wei, Z., Wang, J. (2011): Detection of antibiotic residues in bovine milk by a voltammetric electronic tongue system. Analytica Chimica Acta 694, 46-56. doi: dx.doi.org/10.1016/j.aca.2011.02.053

52. Wei, Z., Wang, J., Zhang, X. (2013): Monitoring of quality and storage time of unsealed pasteurized milk by voltammetric electronic tongue. Electrochimica Acta 88, 231-239. doi: dx.doi.org/10.1016/j.electacta.2012.10.042

53. Winquist, F., Wide, P., Lundström, I. (1997): An electronic tongue based on voltammetry. Analytica Chimica Acta 357, 21-31. doi: dx.doi.org/10.1016/S0003-2670(97)00498-4

54. Winquist, F., Krantz-Rülcker, C., Wide, P., Lundström, I. (1998): Monitoring of freshness of milk by an electronic tongue on the basis of voltammetry. Measurement Science and Technology 9 (12), 1937-1946. doi: dx.doi.org/10.1088/0957-0233/9/12/002

55. Winquist, F., Holmin, S., Krantz-Rülcker, C., Wide, P., Lundström, I. (2000): A hybrid electronic tongue. Analytica Chimica Acta 406, 147-157. doi: dx.doi.org/10.1016/S0003-2670(99)00767-9

56. Winquist, F., Krantz-Rülcker, C., Lundström, I. (2002): Electronic tongues and combinations of artificial senses. Sensors Update 11 (1), 279-306. doi: dx.doi.org/10.1002/seup.200211107

57. Winquist, F., Bjorklund, R., Krantz-Rülcker, C., Lundström, I., Östergren, K., Skoglund, T. (2005): An alectronic tongue in the dairy industry. Sensors and Actuators B 111-112, 299-304. doi: dx.doi.org/10.1016/j.snb.2005.05.003 